This item was submitted to Loughborough's Institutional Repository (https://dspace.lboro.ac.uk/) by the author and is made available under the following Creative Commons Licence conditions.

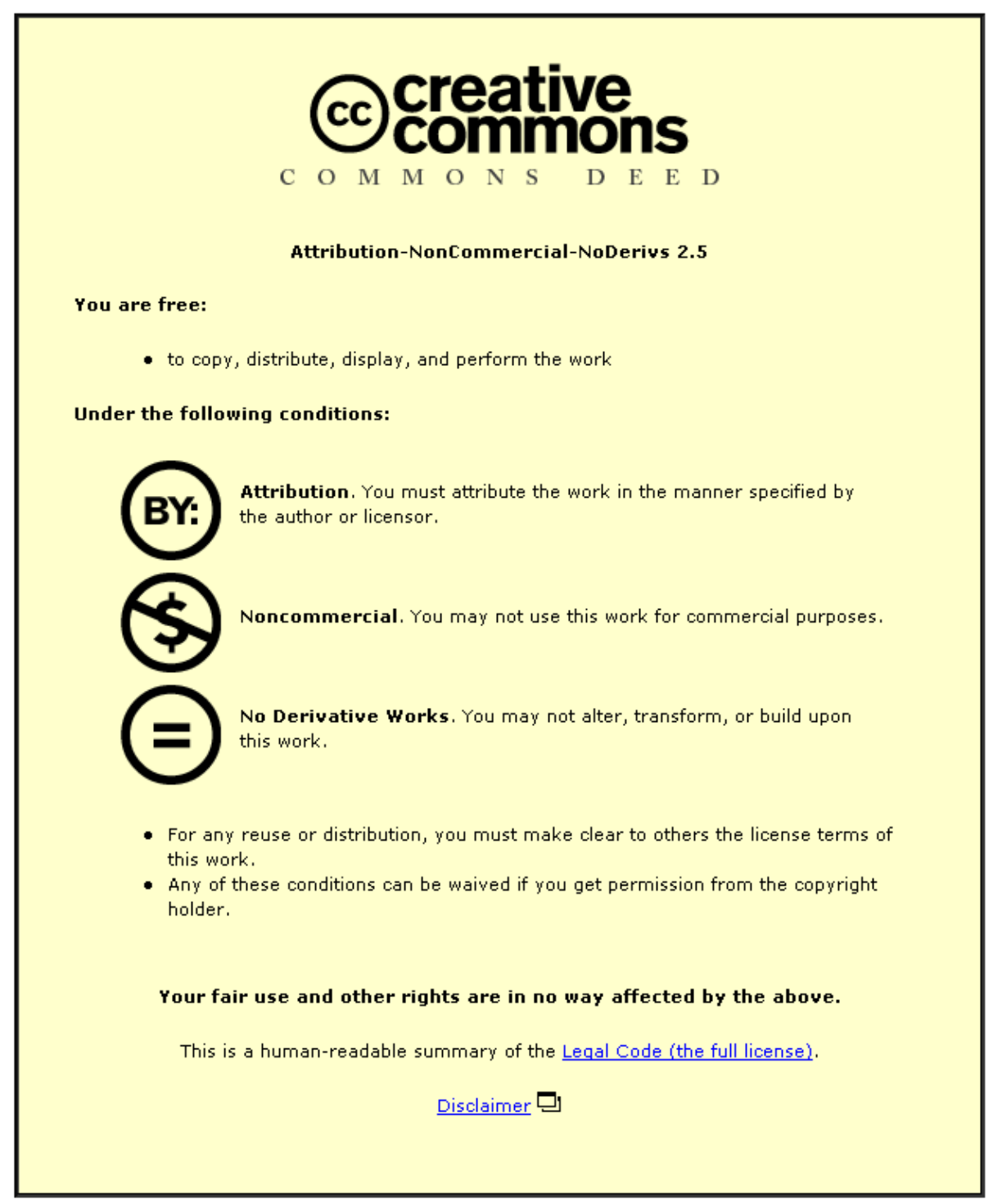

For the full text of this licence, please go to: http://creativecommons.org/licenses/by-nc-nd/2.5/ 


\title{
Reduction of greenhouse gas emissions from UK hotels in 2030
}

\author{
Simon Taylor ${ }^{\mathrm{a},{ }^{*}}$, Andrew Peacock $^{\mathrm{b}}$, Phil Banfill ${ }^{\mathrm{b}}$ and Li Shao ${ }^{\mathrm{a}}$
}

a. Institute of Energy and Sustainable Development, De Montfort University, The Gateway, Leicester LE1 9BH, UK.

b. Energy Academy, Heriot-Watt University, Edinburgh EH14 4AS, UK.

* Corresponding author. Tel.: +44(0)116 207 8836; Fax: +44(0)116 2577981. E-mail address: sctaylor@dmu.ac.uk (Simon Taylor)

\begin{abstract}
The feasibility of halving greenhouse gas emissions from hotels by 2030 has been studied as part of the Carbon Vision Buildings Programme. The aim of that programme was to study ways of reducing emissions from the existing stock because it will be responsible for the majority of building emissions over the next few decades. The work was carried out using detailed computer simulation using the ESP-r tool. Two hotels were studied, one older and converted and the other newer and purpose-built, with the aim of representing the most common UK hotel types.
\end{abstract}

The effects were studied of interventions expected to be available in 2030 including fabric improvements, HVAC changes, lighting and appliance improvements and renewable energy generation. The main finding was that it is technically feasible to reduce emissions by $50 \%$ without compromising guest comfort. Ranking of the interventions was problematical for several reasons including interdependence and the impacts on boiler sizing of large reductions in the heating load.

\section{Keywords}

Building simulation; CO2 emissions; energy; hotels; climate; retrofit; technical feasibility 


\section{Introduction}

The reality of climate change is now widely accepted, along with the likelihood that the cause is greenhouse gas emissions due to human activity. The primary need is for reductions in carbon dioxide emissions from fossil fuel combustion related to heating, electricity generation and transport. Following the RCEP report in 2000 [1], the UK government put into law a $60 \%$ reduction in emissions by 2050 and has since increased the figure to $80 \%$.

Analysis of the source of the emissions shows that, across the EU, at least $40 \%$ are from buildings [2], with a corresponding figure of $47 \%$ in the UK [3]. As a result, a great deal of attention has been directed at buildings, and the UK government has pledged to make all new buildings carbon-neutral: residential buildings by 2016 and the remainder by 2019. However, during the period in which emissions must be drastically reduced, the great majority of buildings will be existing ones.

The Carbon Vision Building programme [4] was established in 2004 with joint sponsorship by the UK Engineering and Physical Sciences Research Council (EPSRC) and the Carbon Trust, an agency set up to help implement the national carbon targets. The programme consisted of three major consortium projects including TARBASE (Technology Assessment for Radically Improving the Built Asset baSE), which was conceived to study ways in which emissions can be reduced from existing buildings. Under the programme, consortia of researchers carried out investigations of technical, social, and market issues relating to low carbon technologies, with emphasis on reliable delivery of major carbon emissions reductions in the built environment. The programme set a target of $50 \%$ carbon emission reduction from UK buildings by 2030 , which was bold at the time of the conception of the project, and this has been since used as a 
reference point rather than an absolute guide. The work reported here is part of the TARBASE project, which focused on technical evaluations of baskets of interventions that would collectively achieve cuts in emissions of at least $50 \%$ in a wide spectrum of both domestic and non-domestic buildings. The types of intervention considered included changes in building fabric and HVAC (heating, ventilation and air conditioning), improved efficiency of lighting and appliances, and renewable energy generation. This paper presents our work on hotels while work on other building types is reported elsewhere, e.g. [5, 6]. A list of all outputs from the project can be found on the TARBASE website [7].

The present work addresses hotels. They were selected because, among non-domestic buildings, they belong to one of the highest emitting sectors [8]. Reasons for the high emissions are likely to include the desire of hotel management to ensure guest comfort and the expectations of guests for a luxury experience without the pressure for energyefficient behaviour that they might experience elsewhere. The area is therefore a challenging one in which to address emission reductions. In recognition of the constraints on hotels, a principle was adopted for the present work that interventions should not compromise guest comfort: almost all of the proposed measures will be invisible to guests when installed.

The approach adopted was to use computer modelling to examine the performance of “exemplars": representative examples of typical buildings. The work was carried out in two stages. Each building was first modelled as accurately as possible for the baseline year of 2005. It was then modelled again for the year 2030, using an appropriate climate, with a range of emission-reducing interventions that are expected to be available as retrofit options.

It is important to note that the present work deals with technical feasibility. Economics 
is not specifically considered, although cost-effectiveness (by current standards) has had an impact on the inclusion and ordering of some interventions.

\section{Building simulation}

\subsection{Hotel selection}

Project resources allowed for two hotel variants to be studied. They were selected by analysing data on hotels in the UK by broad category and selecting the two most common types. Those selected are broadly representative of $67 \%$ of hotels in the UK. Exemplars were designed that contained the main features of the two hotel variants.

The most common hotel type was a business park hotel. The exemplar, referred to in the following as the "newer" hotel, has 126 rooms and was purpose built in 1986 to the construction standards in force then. This means that it has an insulated cavity wall, loft insulation and double glazing. Since it caters to the business community in particular, it also has conference facilities. A sketch of the hotel is shown in Fig. 1(a).

The other (“older") exemplar is a converted city-centre hotel of pre-1900 construction. It has solid walls and single glazing and contains 88 bedrooms. The hotel adjoins other buildings on both wings. A sketch is shown in Fig. 1(b). 
Fig. 1. Sketches of the hotels studied [31]. (a) Newer, purpose-built business park hotel; (b) Older, converted, city-centre hotel
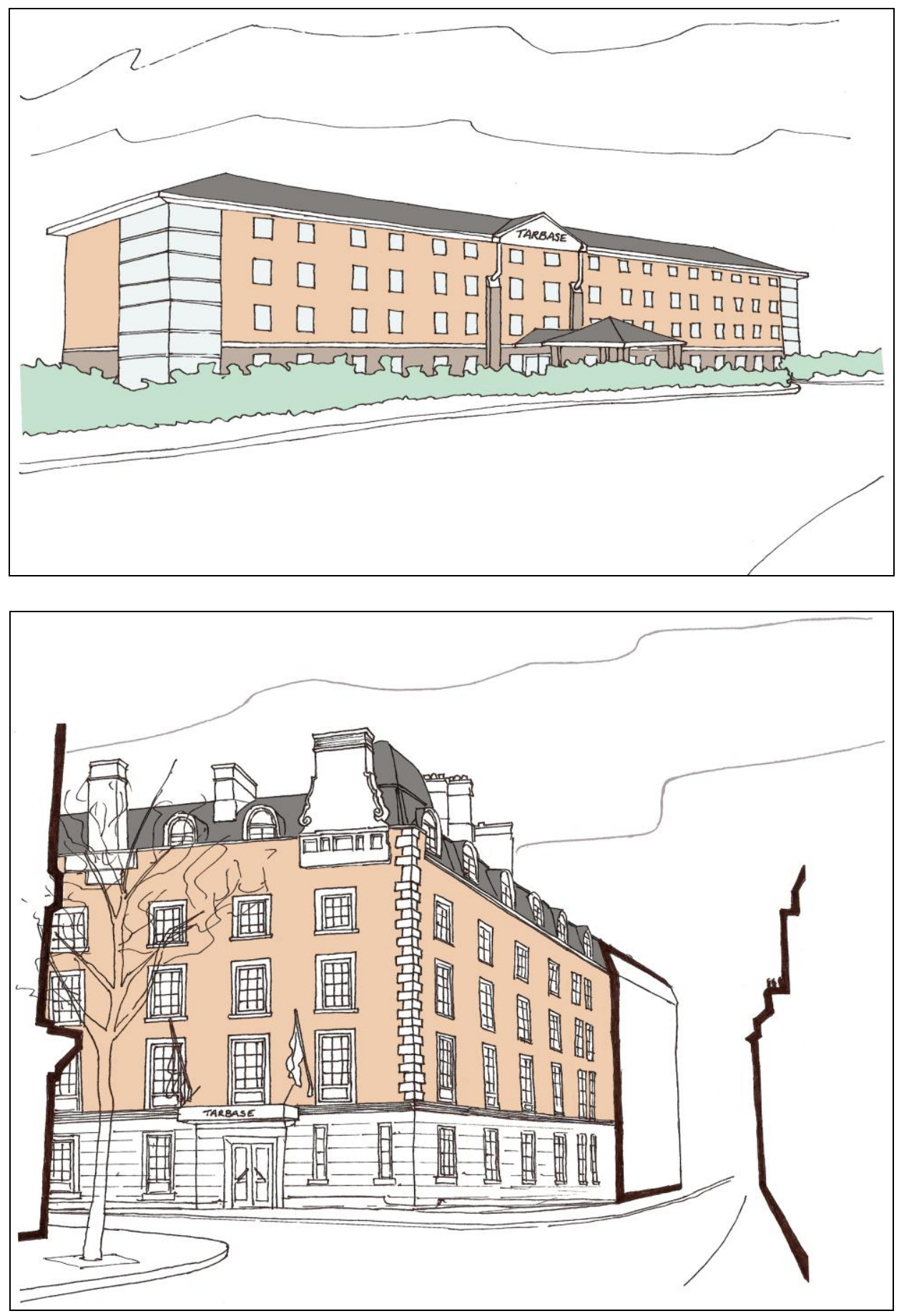

Features common to both hotels are a kitchen, restaurant, bar, administration area, onsite laundry facilities and lifts to all floors. Since the hotels are mid-price rather than luxury standard and operating in the UK, it is assumed that there is no mechanical cooling. 


\subsection{Organization of work}

The building simulation was carried out using ESP-r. Like similar tools such as IES and EnergyPlus, it works on a zonal basis and calculates heat and mass transfers as required over specified periods of time. In the present case, timesteps of 1 hour were used and simulations were performed for the whole of a year, either 2005 or 2030.

The basic ingredients required for a simulation are (a) a building structure with specified materials for the bounding surfaces (walls, glazing, doors); (b) details of the sources of "casual gains": heat from occupants, appliances and lighting; (c) air flow rates due to infiltration and ventilation; and (d) climate data, especially outside air temperature. Heating systems can be represented in a variety of ways. In the present work, set point temperatures were defined for all heated zones and the energy required to achieve the set points was an output from the program. This was then post-processed to produce realistic heating loads by dividing by appropriate seasonal efficiencies. Cooling set points were also defined, but no cooling load was calculated. The assumption was made that, in the UK climate in both 2005 and 2030, adequate cooling could be obtained by use of natural ventilation and following good practice for prevention of overheating.

The nature of both the simulation task and the software meant that it was natural to organize the modelling in two parts: physical models, and casual gains \& airflow. Physical models were set up of the building structures needed for representing the interventions described in Section 2.4. Model representations of the hotels are shown in Fig. 2. Casual gains and air flow data were then included by the methods described below. 
Fig. 2. ESP-r representations of the hotels studied. (a) Newer; (b) Older
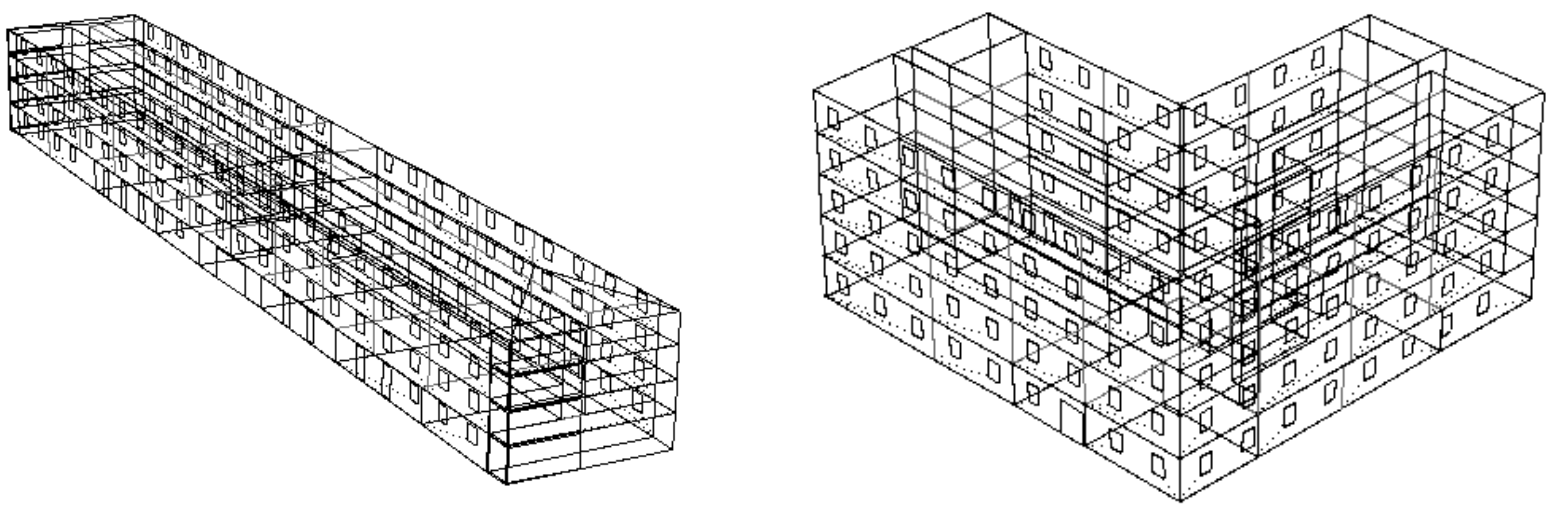

Ventilation heat recovery was modelled by reducing the ventilation air flow rate by the fraction specified for heat recovery, which was $70 \%$ in the standard case. A proof of the validity of this approach is provided in the appendix.

In order to capture the thermal behaviour of the different spaces in the hotels (e.g. kitchens, laundry, conference room, bedrooms and circulation areas) it was necessary to use a relatively large number of zones: 21 in the city centre hotel and 29 in the business park building. The normal maximum number of zones in the ESP-r tool is 28 and a special version which allowed 48 zones was used in all the modelling. Taken with the large number of changes required in the casual gains and air flow data for the different cases being modelled, the entering of the data became a task requiring significant time and concentration and, consequently, one which in which the risk of error was high.

To avoid these difficulties, software was specially written to create directly the files used by ESP-r for transferring casual gains and air flow data to the simulation engine. The details of the software are described elsewhere [9].

The main output of the simulations consisted of the annual heating load for each of the zones in the model. This was post-processed to determine consumption of electricity and gas. $100 \%$ efficiency was assumed for electric heating, while seasonal efficiencies 
of $75 \%$ and $90 \%$ respectively were assumed for the conventional and condensing gas boilers. Carbon dioxide equivalent emissions were then obtained by multiplying by Defra emissions factors [10]. In particular, the long-term marginal factor of $0.43 \mathrm{~kg}$ $\mathrm{CO}_{2} \mathrm{e} / \mathrm{kWh}$ for grid electricity was used $[5,10]$, while the Defra value of $0.185 \mathrm{~kg}$ $\mathrm{CO}_{2} \mathrm{e} / \mathrm{kWh}$ (based on gross $\mathrm{CV}$ ) was used for natural gas. The other output was the total electrical and fossil fuel energy usage by different equipment. This was used for calculating the emissions from the different sources. The end result was a set of direct emissions from gas combustion at the hotel and a set of indirect emissions, which would occur physically at power stations remote from the hotel, resulting from grid electricity usage.

Defra does not provide explicit guidance on future electricity emission factors and the value referred to above was used for modelling indirect emissions in both 2005 and 2030. Possible variations in the 2030 value were captured in the sensitivity analysis described later.

Areas specifically not covered in the work include cooling (as described earlier), shading, dehumidification and variations in occupancy through the year. All would be of interest but were not considered crucial for the aims of the present work.

\subsection{Base conditions}

The base conditions for both hotels included the use of a 2005 climate for Birmingham (UK) which was taken from the 1995 TRY weather files.

Building structures used in the modelling work were drawn from CIBSE Guide A [11]. The newer hotel had walls of brick and block construction with an insulated cavity, along with double glazed windows and a well-insulated roof space. The assumption was made that any "quick wins" such as loft insulation would have been taken already by 
2005. The older hotel had solid walls of $220 \mathrm{~mm}$ thickness with single glazed windows and limited roof insulation because the roof is immediately above the top floor. The thermal properties of the various building elements are shown in Table 1 along with those adopted for the insulation intervention described later.

Table 1. $U$-values / $\mathrm{Wm}^{-2} \mathrm{~K}^{-1}$ of building elements

\begin{tabular}{ccccc}
\hline & \multicolumn{2}{c}{ Newer hotel } & \multicolumn{2}{c}{ Older hotel } \\
\cline { 2 - 5 } & 2005 & 2030 & 2005 & 2030 \\
\hline Walls & 0.453 & 0.180 & 2.352 & 0.583 \\
Glazing & 2.811 & 0.610 & 5.621 & 0.610 \\
Floor & 0.241 & 0.241 & 1.283 & 1.283 \\
Roof & 0.130 & 0.130 & 0.446 & 0.446 \\
\hline
\end{tabular}

The bedrooms contained the type of equipment normally available in mid-price hotels such as a television, minibar, hairdryer, shaving socket and trouser press. In the absence of detailed information on guest behaviour with respect to appliance and mobile equipment use, available data $[12,13]$ was supplemented with reasonable assumptions about the use of televisions, hairdryers and kettles and of power sockets for using laptops and charging mobile equipment. The overall impact was checked at the validation stage (Section 4.2) and tested using sensitivity analysis.

The number of hotel staff was estimated using data of Lockyer and Scholarios [14]. Guest occupancy of the hotels was deduced by applying the results of the UK occupancy survey [15] to the number of guest bedrooms. Two cases were considered: full (equivalent to 1.48 people per bedroom) and average. Simulations showed that the level of occupancy had a significant effect on the results. Since the aim was to 
determine greenhouse gas emissions for average conditions, maximum occupancy was not appropriate. However, decreasing the occupancy to average with no other changes would also be unrealistic because sensible management would reduce costs by closing off certain rooms, and would use zonal controls to leave them unheated and minimally ventilated. A set of rooms that would be closed off was therefore defined for each hotel, and the rest of the modelling used this arrangement.

In order to be realistic, the modelling required both infiltration and ventilation to be modelled. Since both are derived in the present case from external air, the ESP-r “infiltration" function was used because it allows a stated flow rate of external air into the zone of interest. Infiltration was based on data in the 1999 edition of CIBSE Guide A [16]. Values for the different room types were between 0.5 and 2.0 air changes per hour, with the majority having values of 1.0. The values were determined for all zones and then any further variations were accomplished by multiplying all values by a given factor. The main use of this function was to simulate the reduction in infiltration due to the insulation intervention, when a reduction of $50 \%$ was used.

It was assumed that mechanical ventilation was used in both hotels, though without any cooling. The ventilation was assumed to be to the standards described in the 1999 edition of CIBSE Guide A [16] for 2005 and the 2006 edition [11] for 2030, supplemented in both cases by CIBSE Guide B2 [17]. Ventilation rates were set so as to achieve recommended values when combined with any pre-existing infiltration. In some cases, in the circulation areas for example, this meant that no ventilation was needed because infiltration exceeded the recommended fresh air flow rate.

Casual gains appropriate to the various types of hotel equipment were included. Catering equipment in the kitchen included gas ovens, electric ovens, fryers, hobs and refrigeration. Professional washing machines in the laundry used hot water from the 
hotel's domestic hot water system. The laundry also used electric tumble dryers. Two electric passenger lifts were used in the newer hotel and one in the older one, while both had a single service lift.

Many hotels have started to make reductions in energy usage, and accordingly most lighting in the hotels in 2005 was by compact fluorescent lamps (CFLs). An engineering consultancy was used to obtain advice on the likely heating system that would exist in such hotels. The advice was that electric heating was common in such buildings. In order to provide a representative range of results, the newer hotel was assumed to be electrically heated and the older one to use a conventional gas boiler.

\subsection{Interventions}

A selection of interventions was used, in common with other TARBASE work [5], that was based on existing technologies or those likely to be widely available by 2030 .

The first change made in the hotel modelling in 2030 was the imposition of base 2030 conditions, which included two effects. One was a 2030 climate for Birmingham, using a weather file created by Jenkins et al [5] by applying the morphing algorithm of Belcher et al [18] to the 2005 file. The other was the application of the 2006 ventilation standards referred to above. The base 2030 conditions were applied at this stage to allow their effects to be seen before the interventions were applied, and to provide the appropriate background for the changes.

The first of the interventions proper was ventilation heat recovery. Considerable amounts of heat are used for warming cool air that enters buildings, either intentionally as ventilation or unintentionally as infiltration. By transferring heat from exhaust to fresh air, large energy savings can be made. The most effective method is a thermal wheel, which can reliably recover $75 \%$ of the available heat, though in the present work 
a value of $70 \%$ has been assumed. Thermal wheels can also help preserve "coolth" in the summer when it is hotter outside than in, and this effect is captured by the present modelling. Allowance was made for the associated power consumption of the thermal wheel.

The next intervention was a package of insulation and glazing measures. Wall insulation was applied, externally in the case of the newer business park hotel and internally to the older city-centre building to avoid affecting its external appearance. The external cladding consisted of $100 \mathrm{~mm}$ of expanded polystyrene with a rendered finish, while the internal wall insulation consisted of $50 \mathrm{~mm}$ of mineral fibre covered by plasterboard. Argon-filled triple glazing was applied to both hotels, replacing double glazing in the newer building and single glazing in the older one. In tests, further enhancement of the loft insulation had negligible effect and so was not used. The $U$-values of the 2005 and 2030 building elements are shown in Table 1.

An additional consequence of making such changes is lower infiltration, and a reduction of $50 \%$ was included as part of the package. Data on air infiltration rates before and after refurbishments are scarce, particularly for non-domestic buildings such as hotels. Our assumption of $50 \%$ reduction in air infiltration resulting from refurbishment is based on the following considerations. The average air infiltration rate is proportional to building air leakage rate (in air changes per hour $(\mathrm{ACH})$ ) or air permeability of buildings (in $\mathrm{m}^{3} / \mathrm{m}^{2} / \mathrm{h}$ ) [11]. The mean air leakage rate of UK dwellings is known to have dropped from over $16 \mathrm{ACH} @ 50 \mathrm{~Pa}$ for houses built in the 1950 s to about 10 $\mathrm{ACH}$ in the 1990s $[19,20]$. Houses with air infiltration rate of about $3 \mathrm{ACH}$ or $3 \mathrm{~m}^{3} / \mathrm{m}^{2} / \mathrm{h} @ 50$ Pa have been achieved in the UK showing that a further $67 \%$ reduction compared with the requirement in the current Building Regulations (2006) is possible even today $[19,21]$. Actually this level of air tightness is routine in Sweden and some other European countries. We believe that the same level of air tightness could be 
routinely achieved in 2030 for hotels, not only because of the many similarities between the construction of the two building types but also because dwellings are among the more difficult to make airtight, in terms of, e.g., air permeability standards specified in CIBSE TM23 for various building types [22]. Similar considerations were applied in TARBASE work on offices [5].

A "power and lighting" intervention (referred to subsequently as P \& L to avoid confusion) consisted of efficiency improvements in lighting, electrical appliances and kitchen catering equipment, both electric and gas-powered. Lighting was assumed to be by LED or an equivalent low-power source, with luminous intensities following those used in other TARBASE work [5, 6]. Tumble dryers were switched from electric to gas powered. Predicted appliance efficiency improvements drew on data from EU projects on energy-using appliances for refrigeration, dishwashers and washing machines [23] and catering equipment [24]. Further catering data came from Deru et al [25], CEEP [26] and Fisher [27]. The lifts were upgraded with more efficient motors for 2030 using data from CIBSE [11]. Commercial vacuum cleaners used by the cleaning staff in 2005 were assumed to benefit in 2030 from higher-efficiency motors. However, no specific data could be obtained and an overall 10\% improvement was assumed in this case.

Following the P \& L intervention, a switch was made from electric or conventional gas heating to the use of a condensing boiler. To maintain simplicity, a seasonal efficiency of $90 \%$ was assumed. Part-load calculations would be needed for a more accurate view, and their use is discussed later.

Finally, water heating using solar thermal collectors was introduced. A simple approach based on the BREDEM-12 model [28] was used, with the key parameter being the area of panels available. For the city centre hotel it was assumed that three-quarters of the flat roof space was available for the panels, with the further assumption that each $1 \mathrm{~m}$ 
width of panel required $1.5 \mathrm{~m}$ of roof space. For the business park hotel in its default north-south orientation, there was very little suitable roof area available. The assumption was made that part of the car park could be used by mounting the panels on a canopy which would also provide sheltered parking.

\section{Results}

\subsection{Establishment of 2005 base case}

As described above, the emissions from the hotels were found to vary significantly with occupancy. Figure 3 shows the effect on the emissions from the newer hotel of reducing the occupancy level from maximum to average and then closing off some zones. Similar results were obtained for the older hotel.

It is interesting that the heating emissions increased when the occupancy was reduced. This was due to the extra load on the heating system due to the reduced casual gains from occupants. There was, however, a net decrease in emissions due to reduced hot water and electrical equipment usage. The further reductions on closing off zones are mainly attributable to the reduced heating load.

The final arrangement with average occupancy and some closed zones was used as the 2005 base case for both hotels for all subsequent simulations. 
Fig. 3. Effect of occupancy change and zone closure on annual emissions from the newer hotel

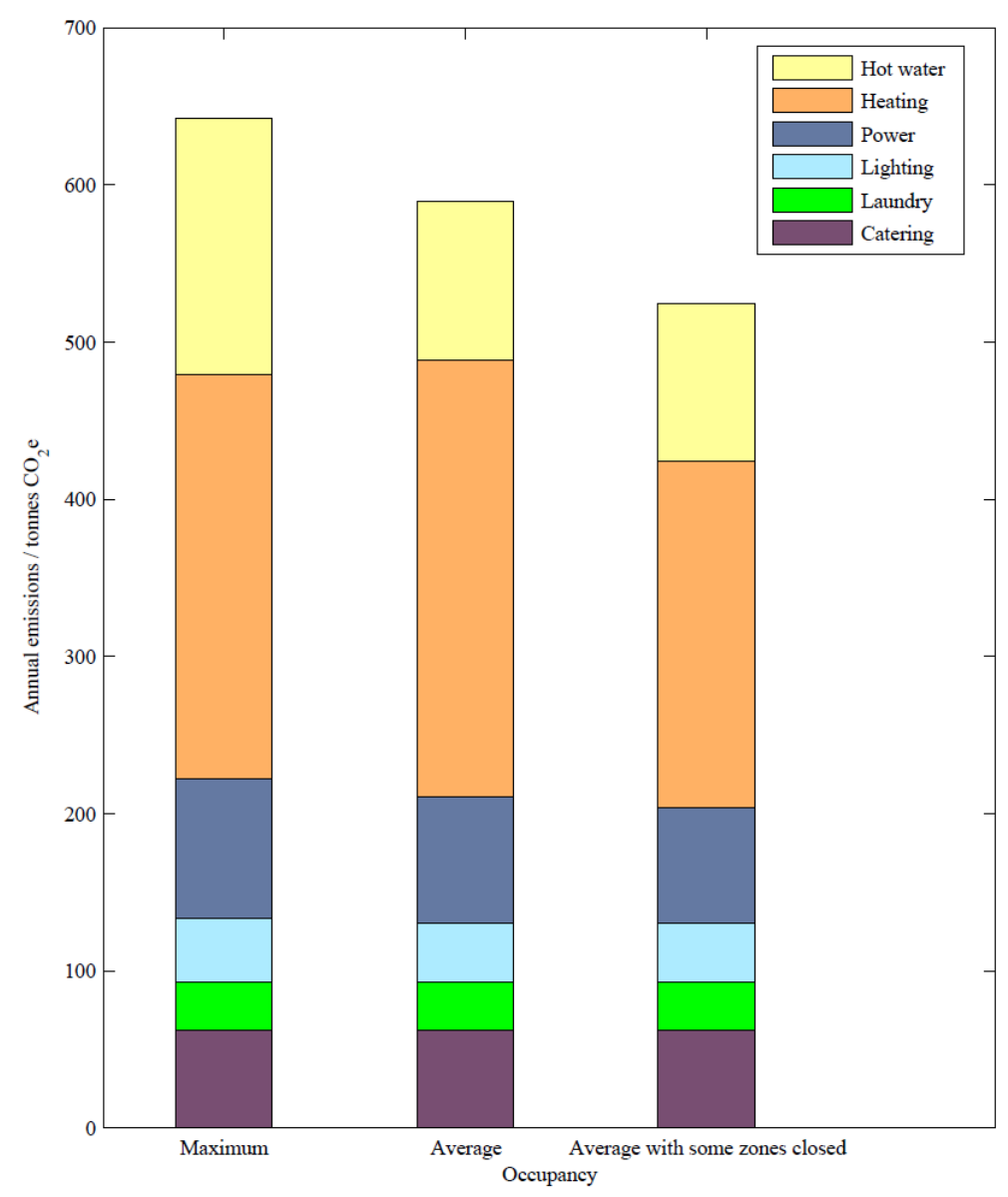

\subsection{Validation}

In order to validate the modelling results, the 2005 base values were compared with the results of a survey of over 50 UK hotels [29]. The survey shows that most hotels surveyed used gas for heating, and the detailed comparisons were therefore made with the older city-centre hotel of the present work which was heated by a conventional gas boiler. An initial finding was that the energy used for catering in the survey exceeded that in the modelling, and the amount of kitchen equipment was modified to provide a better match.

Figure 4 compares the proportions of energy consumed by a range of activities in the final model with those in the survey sample, using the prescribed categories. Figure 5 
examines the same data in a different way by comparing energy use per unit floor area.

The main difference between model and survey is in the lighting, where the modelled value is roughly half of that in the survey. The reason is the employment in the model of low-energy compact fluorescent lamps which were little used at the time of the survey.

Given the spread in values within the survey, the agreement is good and suggests that the model predictions are in line with measured values.

Fig. 4. Comparison of proportions of energy use in model with survey
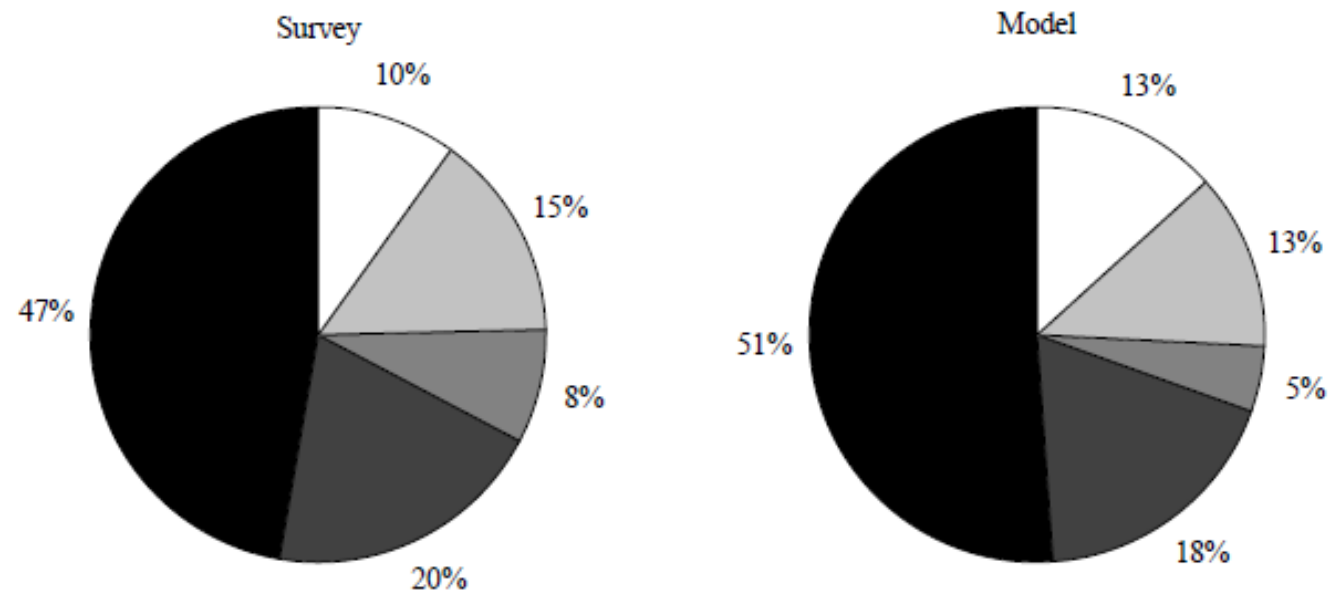

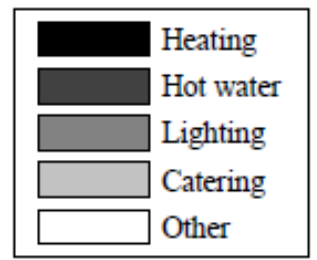


Fig. 5. Comparison of annual energy consumption per unit area of model with survey

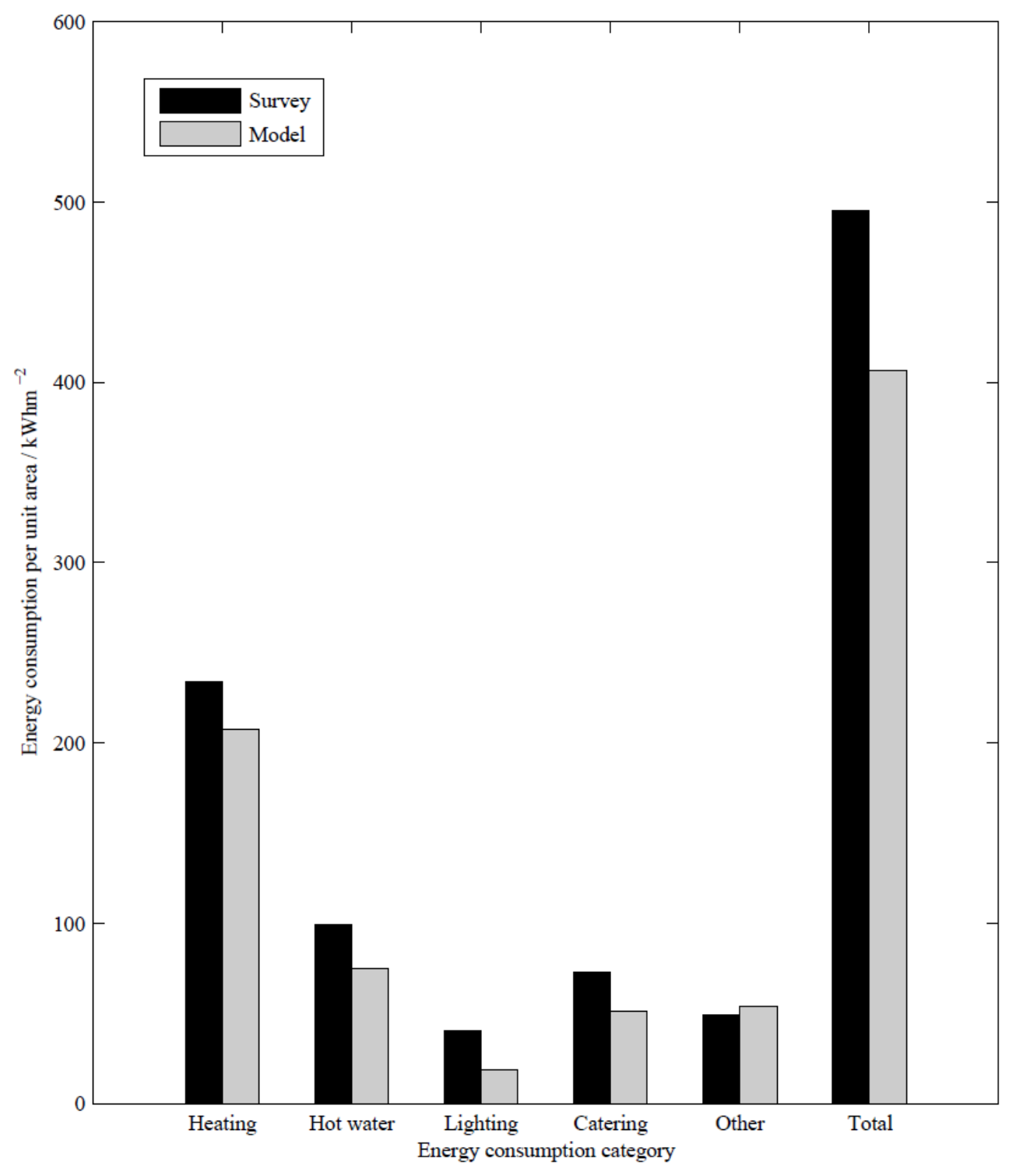

\subsection{Effect of interventions}

Figures 6 and 7 show the effects of the 2030 climate and the interventions on the two hotels studied in the present work.

The effect on the emissions of the switch to the 2030 base conditions was small. The only item affected was the heating, the emissions from which decreased marginally as a result of a reduction in energy use of about $5 \%$. However, this is the result of two opposing effects: a warmer climate and greater heat loss due to increased ventilation to 
meet post-2005 standards. Additional calculations for the newer hotel which excluded the ventilation change show that the decrease in heating energy consumption due to climate change alone was $11 \%$. Similar results would be expected for the older hotel. If mechanical cooling had been included, there would have been a corresponding increase in emissions due to the extra cooling required in the warmer climate.

Fig. 6. Effect of interventions on newer hotel. (a) annual emissions; (b) annual energy consumption
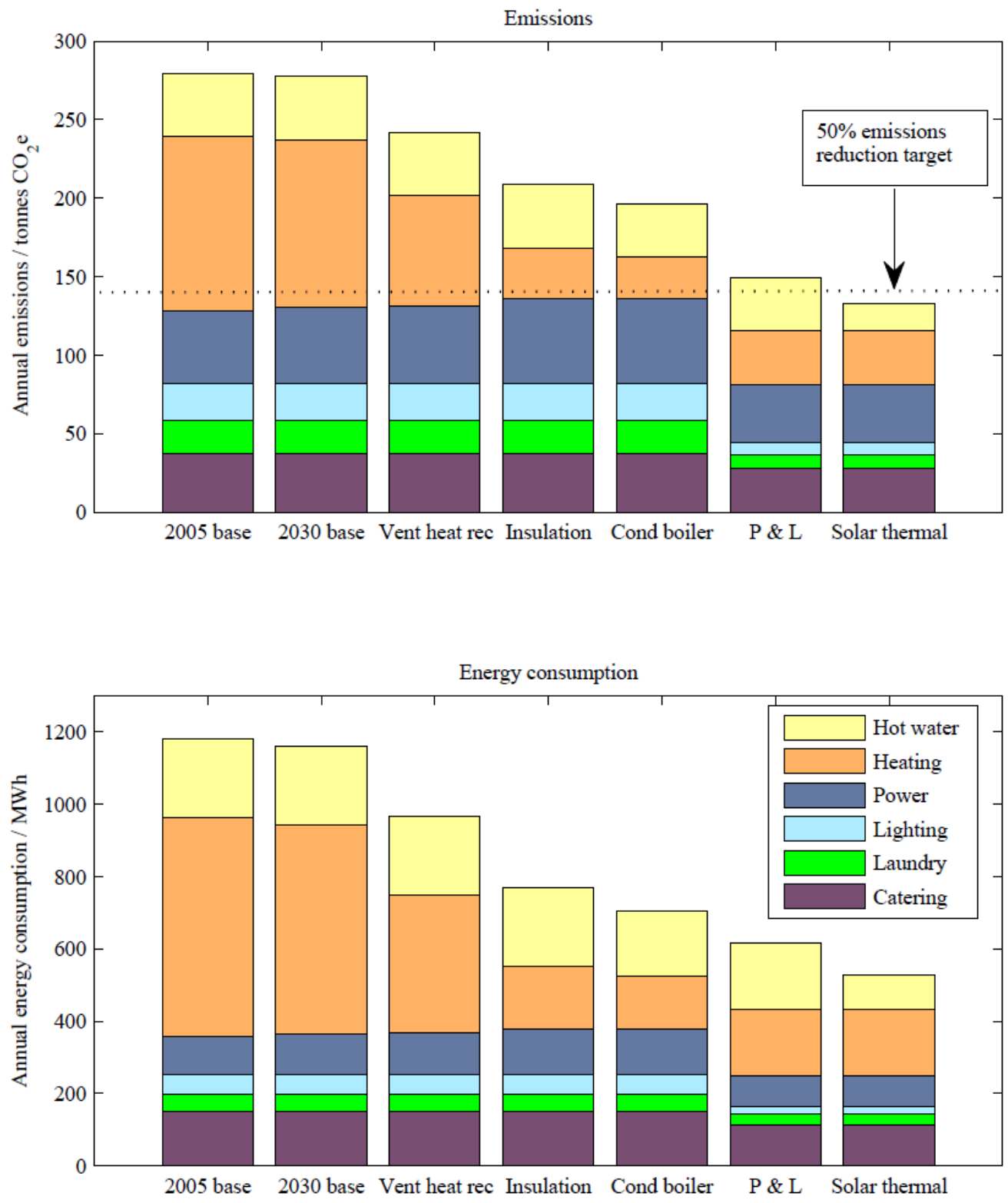
Fig. 7. Effect of interventions on older hotel. (a) annual emissions; (b) annual energy consumption
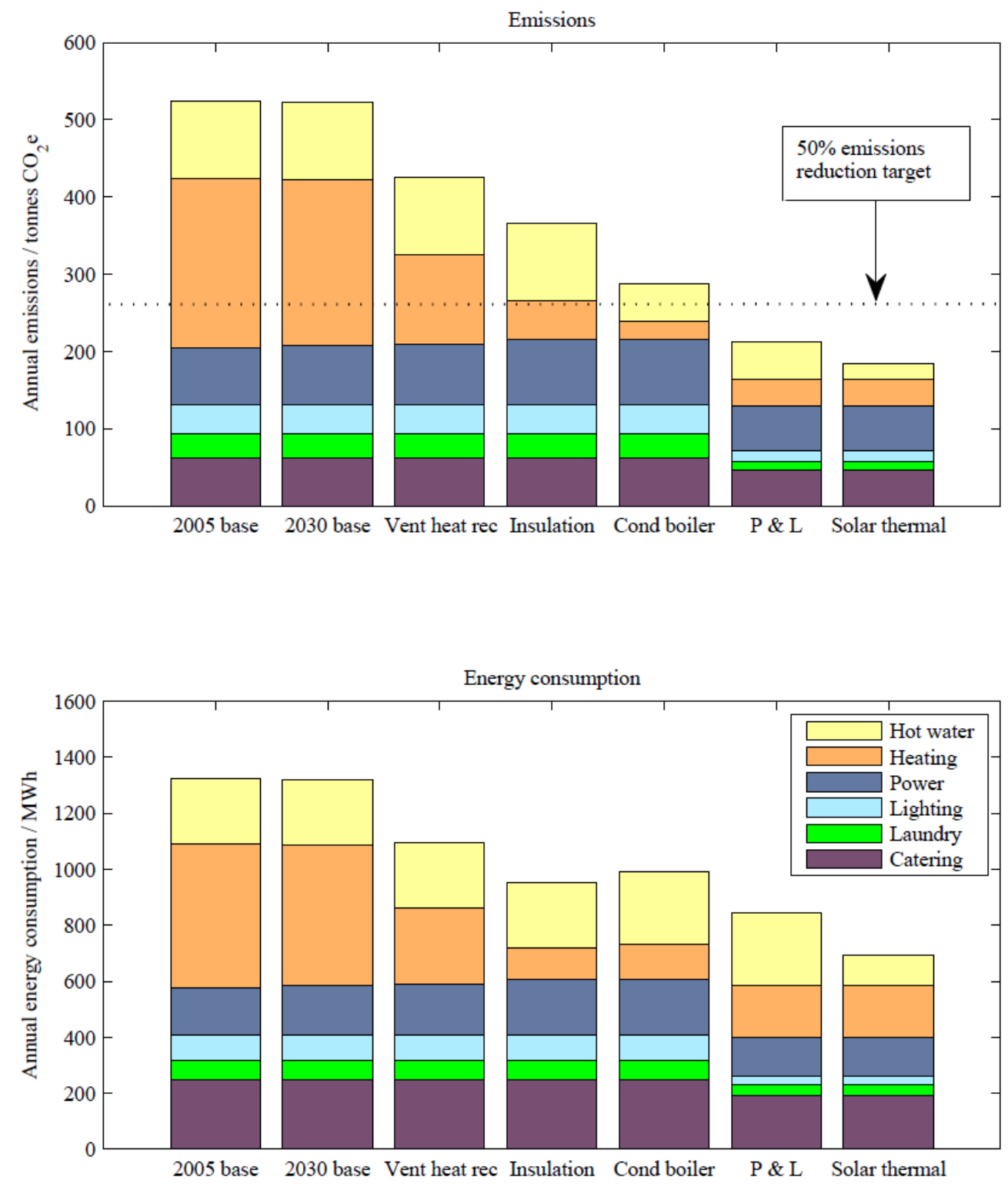

Each of the interventions led to a significant reduction in emissions except for the installation of a condensing boiler in the older hotel. The unit being replaced was a conventional gas boiler, so the improvement was due to a relatively small change in efficiency.

A key feature of both sets of results in Figs. 6(b) and 7(b) is the significant reduction in the heating load as a result of the ventilation heat recovery and insulation interventions. 
The insulation package consisted of three separate effects: the addition of wall insulation (external in the newer hotel, internal in the older), upgrading to Ar-filled triple glazing, and reduction in infiltration as a consequence of these changes. It is interesting to look at these effects in more detail. Figure 8 shows the proportion of the total emissions savings for which each ingredient is responsible. In both hotels it is the infiltration reduction that provides the biggest benefit. It can also be seen that the benefit of further wall insulation on the newer hotel is small.

Fig. 8. Contribution to emissions reduction of the elements of the insulation package

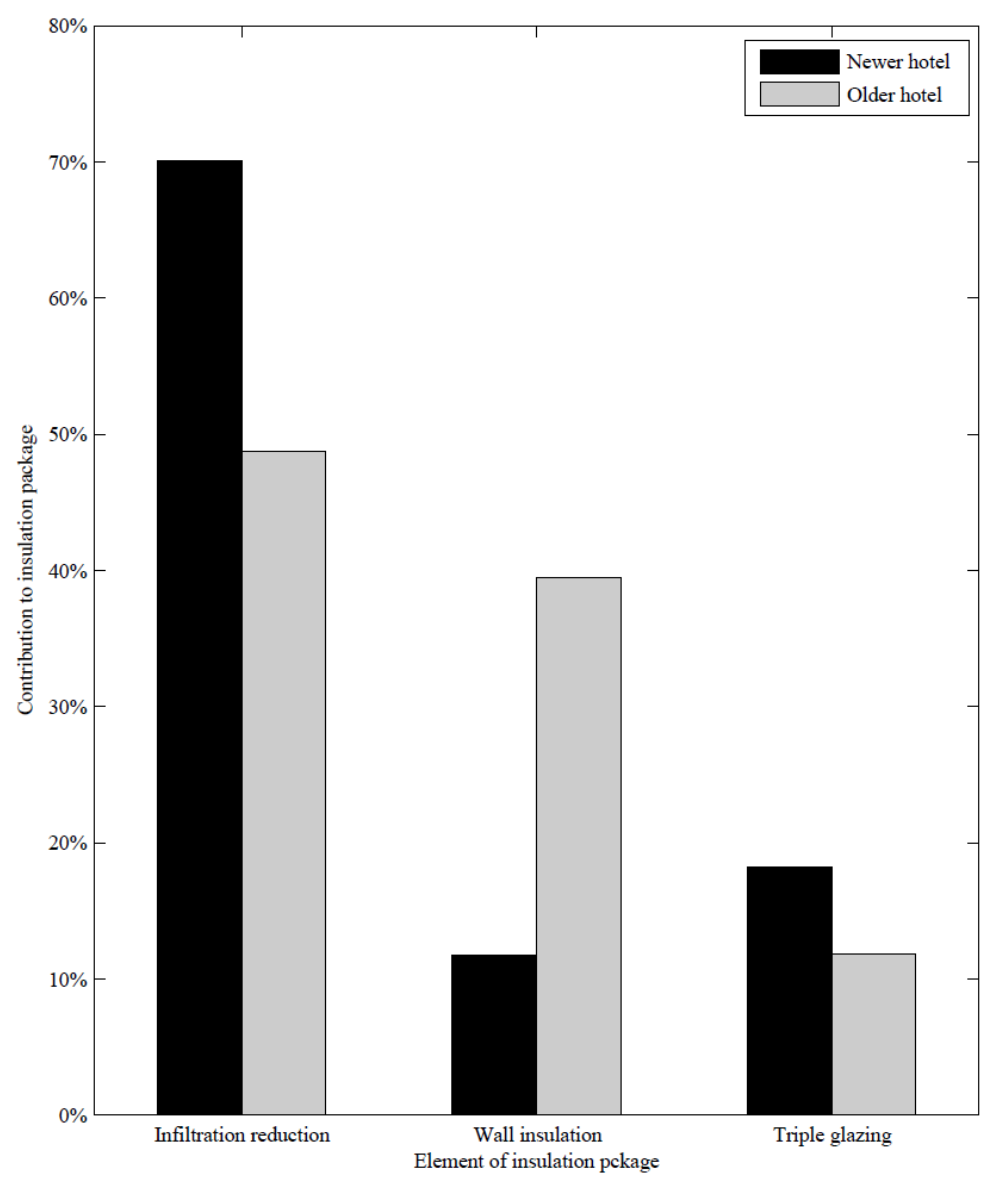

Overall, emissions reductions of more than $50 \%$ were achieved for both hotels, although fewer interventions were needed in the newer electrically-heated one where the switch to gas heating provided a significant emissions saving. 
Computations were also carried out using alternative heating methods: electrical heating in the older hotel and gas heating in the newer. The results when the two hotels used the same heating method were very similar and for that reason are not presented.

\subsection{Change in intervention order}

The interventions described were carried out in a specific order which was a compromise taking into account cost, practical advantages and immediate demonstration of benefits. This last point is considered further here. It turned out that in some alternative orderings the full benefit of an intervention was not realized until a subsequent intervention had been applied.

Consider the newer hotel after the insulation intervention has taken place. As shown in Fig. 6, the next two interventions are Condensing Boiler then P \& L. From Table 2, the corresponding emission reductions are 78.4 and $75.8 \mathrm{tCO}_{2} \mathrm{e}$ respectively. If the computations are repeated with the interventions applied in the opposite order, the reductions are $64.2 \mathrm{tCO}_{2} \mathrm{e}$ for $\mathrm{P} \& \mathrm{~L}$ and $90.0 \mathrm{tCO}_{2} \mathrm{e}$ for the condensing boiler. The total reduction in both cases is $154.2 \mathrm{tCO}_{2} \mathrm{e}$ since the combined effect must be orderindependent. However, the reductions associated with the interventions depend on the order in which they are made. The P \& L intervention achieves a reduction of 75.8 $\mathrm{tCO}_{2} \mathrm{e}$ when carried out after the condensing boiler but only $64.2 \mathrm{tCO}_{2} \mathrm{e}$ before, a difference of $11.6 \mathrm{tCO}_{2} \mathrm{e}$.

The implications of the above findings are discussed in Section 4.4. 
Table 2. Results for newer hotel. (a) Annual greenhouse gas emissions; (b) Annual energy consumption

\begin{tabular}{lccccccc}
\hline & \multicolumn{7}{c}{ Annual GHG emissions / tonnes $\mathrm{CO}_{2} \mathrm{e}$} \\
\cline { 2 - 8 } & Catering & Laundry & Lighting & Power & Heating & Hot water & Total \\
\hline Base case 2005 & 62.2 & 30.5 & 38.0 & 73.4 & 220.0 & 100.5 & 524.6 \\
\hline 2030 climate & 62.2 & 30.5 & 38.5 & 76.8 & 214.0 & 100.5 & 522.5 \\
\hline $\begin{array}{l}\text { Ventilation heat } \\
\text { recovery }\end{array}$ & 62.2 & 30.5 & 38.5 & 78.0 & 116.6 & 100.5 & 426.2 \\
\hline Insulation & 62.2 & 30.5 & 38.5 & 84.5 & 49.8 & 100.5 & 365.9 \\
\hline Condensing boiler & 62.2 & 30.5 & 38.5 & 84.5 & 23.8 & 48.0 & 287.5 \\
\hline Power \& lighting & 46.3 & 11.1 & 13.5 & 58.4 & 34.4 & 48.0 & 211.7 \\
\hline Solar thermal & 46.3 & 11.1 & 13.5 & 58.4 & 34.4 & 19.8 & 183.4 \\
\hline
\end{tabular}

\begin{tabular}{lccccccc}
\hline & \multicolumn{7}{c}{ Annual energy consumption / MWh } \\
\cline { 2 - 8 } & Catering & Laundry & Lighting & Power & Heating & Hot water & Total \\
\hline Base case 2005 & 247.7 & 71.0 & 88.3 & 170.8 & 511.7 & 233.7 & 1323.2 \\
\hline 2030 climate & 247.7 & 71.0 & 89.4 & 178.7 & 497.7 & 233.7 & 1318.2 \\
\hline $\begin{array}{l}\text { Ventilation heat } \\
\text { recovery }\end{array}$ & 247.7 & 71.0 & 89.4 & 181.3 & 271.2 & 233.7 & 1094.4 \\
\hline Insulation & 247.7 & 71.0 & 89.4 & 196.5 & 115.7 & 233.7 & 954.0 \\
\hline Condensing boiler & 247.7 & 71.0 & 89.4 & 196.5 & 128.6 & 259.6 & 992.9 \\
\hline Power \& lighting & 190.1 & 40.8 & 31.4 & 135.8 & 186.0 & 259.6 & 843.7 \\
\hline Solar thermal & 190.1 & 40.8 & 31.4 & 135.8 & 186.0 & 106.8 & 690.9 \\
\hline
\end{tabular}

Table 3. Results for older hotel. (a) Annual greenhouse gas emissions; (b) Annual energy consumption

\begin{tabular}{lccccccc}
\hline & \multicolumn{7}{c}{ Annual GHG emissions / tonnes $\mathrm{CO}_{2} \mathrm{e}$} \\
\cline { 2 - 8 } & Catering & Laundry & Lighting & Power & Heating & Hot water & Total \\
\hline Base case 2005 & 37.4 & 21.3 & 23.1 & 46.1 & 111.4 & 40.2 & 279.6 \\
\hline 2030 climate & 37.4 & 21.3 & 23.4 & 48.3 & 106.8 & 40.2 & 277.4 \\
\hline $\begin{array}{l}\text { Ventilation heat } \\
\text { recovery }\end{array}$ & 37.4 & 21.3 & 23.4 & 49.4 & 70.3 & 40.2 & 242.0 \\
\hline Insulation & 37.4 & 21.3 & 23.4 & 53.7 & 32.4 & 40.2 & 208.4 \\
\hline Condensing boiler & 37.4 & 21.3 & 23.4 & 53.7 & 27.0 & 33.5 & 196.3 \\
\hline Power \& lighting & 27.8 & 8.4 & 8.1 & 37.1 & 34.3 & 33.5 & 149.2 \\
\hline Solar thermal & 27.8 & 8.4 & 8.1 & 37.1 & 34.3 & 17.1 & 132.8 \\
\hline
\end{tabular}

\begin{tabular}{lccccccc}
\hline & \multicolumn{7}{c}{ Annual energy consumption / MWh } \\
\cline { 2 - 8 } & Catering & Laundry & Lighting & Power & Heating & Hot water & Total \\
\hline Base case 2005 & 148.9 & 49.6 & 53.8 & 107.3 & 602.3 & 217.3 & 1179.2 \\
\hline 2030 climate & 148.9 & 49.6 & 54.5 & 112.2 & 577.2 & 217.3 & 1159.8 \\
\hline $\begin{array}{l}\text { Ventilation heat } \\
\text { recovery }\end{array}$ & 148.9 & 49.6 & 54.5 & 114.9 & 379.8 & 217.3 & 965.0 \\
\hline Insulation & 148.9 & 49.6 & 54.5 & 124.8 & 175.0 & 217.3 & 770.1 \\
\hline Condensing boiler & 148.9 & 49.6 & 54.5 & 124.8 & 145.9 & 181.1 & 704.7 \\
\hline Power \& lighting & 114.2 & 29.5 & 18.9 & 86.2 & 185.4 & 181.1 & 615.3 \\
\hline Solar thermal & 114.2 & 29.5 & 18.9 & 86.2 & 185.4 & 92.3 & 526.5 \\
\hline
\end{tabular}




\subsection{Sensitivity analysis}

Sensitivity analysis was used to check the reliability of the results by highlighting where they depended strongly on input data. Most of the areas selected for investigation were those for which the values used were relatively uncertain. For example, the level assumed for usage of laptop computers and charging of mobile phones and other portable electronic devices in 2030 , though based on literature values, is unlikely to be accurate because future trends in such usage are difficult to predict. So in this case, the impact on the results of doubling the assumed usage has been calculated. The results are shown in Fig. 9 along with results for some other input data of interest.

Fig. 9. Sensitivity of annual emissions to possible changes in input values

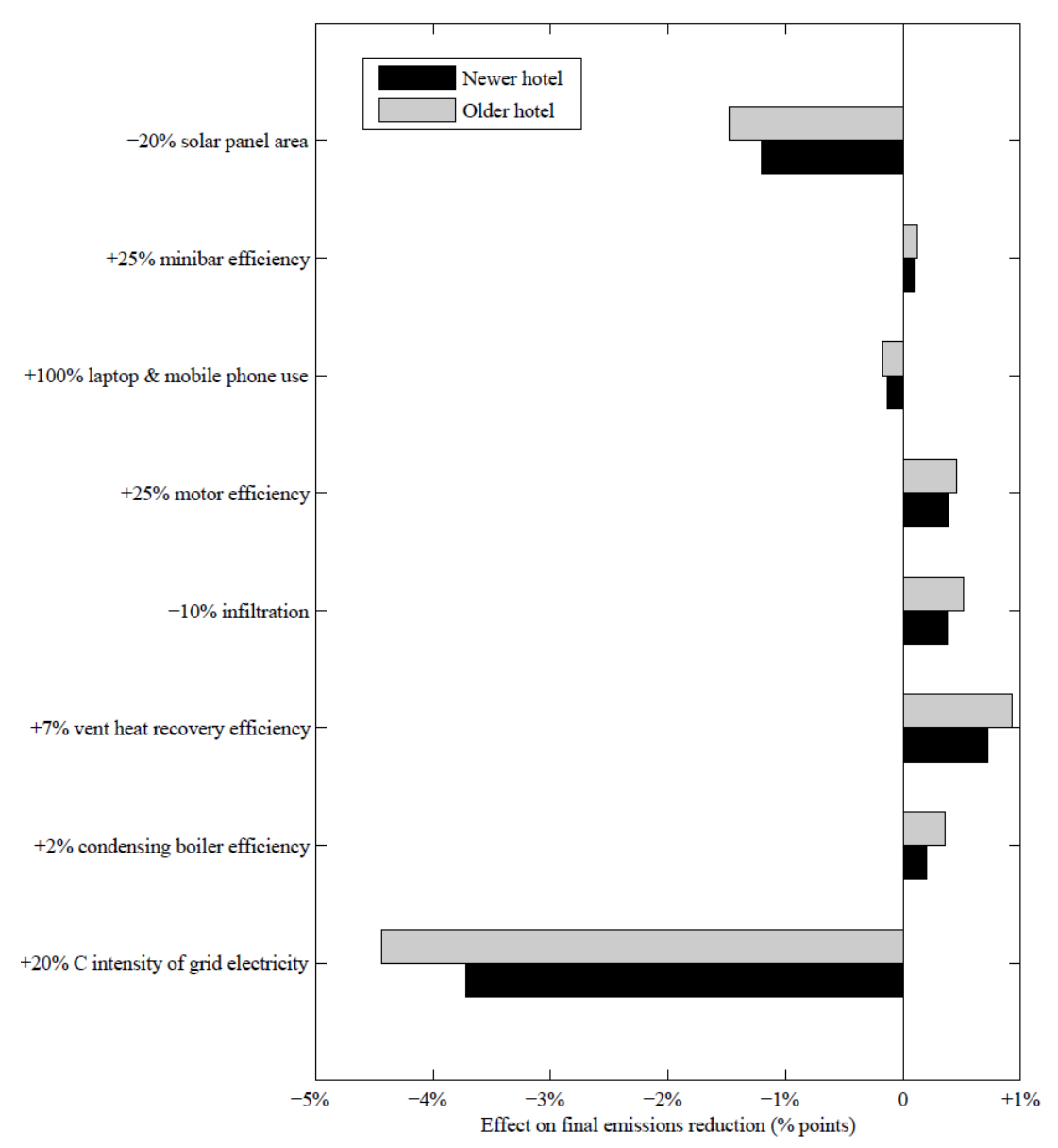


The most significant result is the effect of an increase in grid carbon intensity of $20 \%$, which would represent the effect of increasing the proportion of coal-powered generation without carbon capture. The change in the emissions reduction for the older city centre hotel is enough to prevent the target of $50 \%$ reductions being achieved. Further calculation shows that the increase in carbon intensity that causes the emissions reduction to just fail to reach $50 \%$ is $15 \%$.

The effect of different grid carbon intensities is shown in Fig. 10 for the whole set of interventions for the newer hotel. A point that comes out clearly is that the sensitivity to carbon intensity decreases with the number of interventions.

Fig. 10. Effect of grid electricity carbon intensity on annual emissions

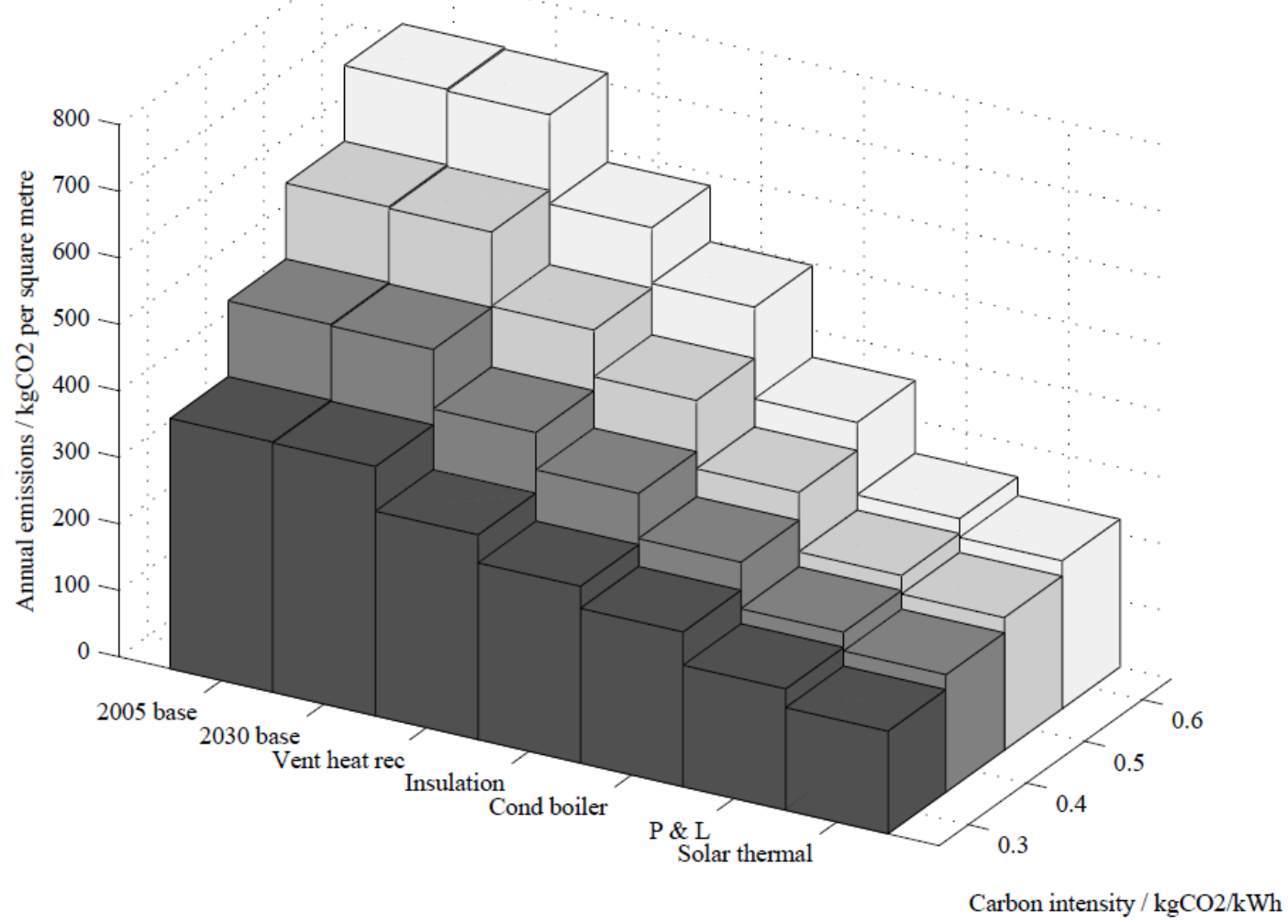

\subsection{Remaining emissions contributions}

The proportions of remaining emissions after all interventions have been applied to the two hotels are shown in Fig. 11. Around half of the remaining emissions were from 
electricity (slightly more for the newer hotel and slightly less for the older one).

Fig. 11. Proportions of final emissions for both hotels after all interventions
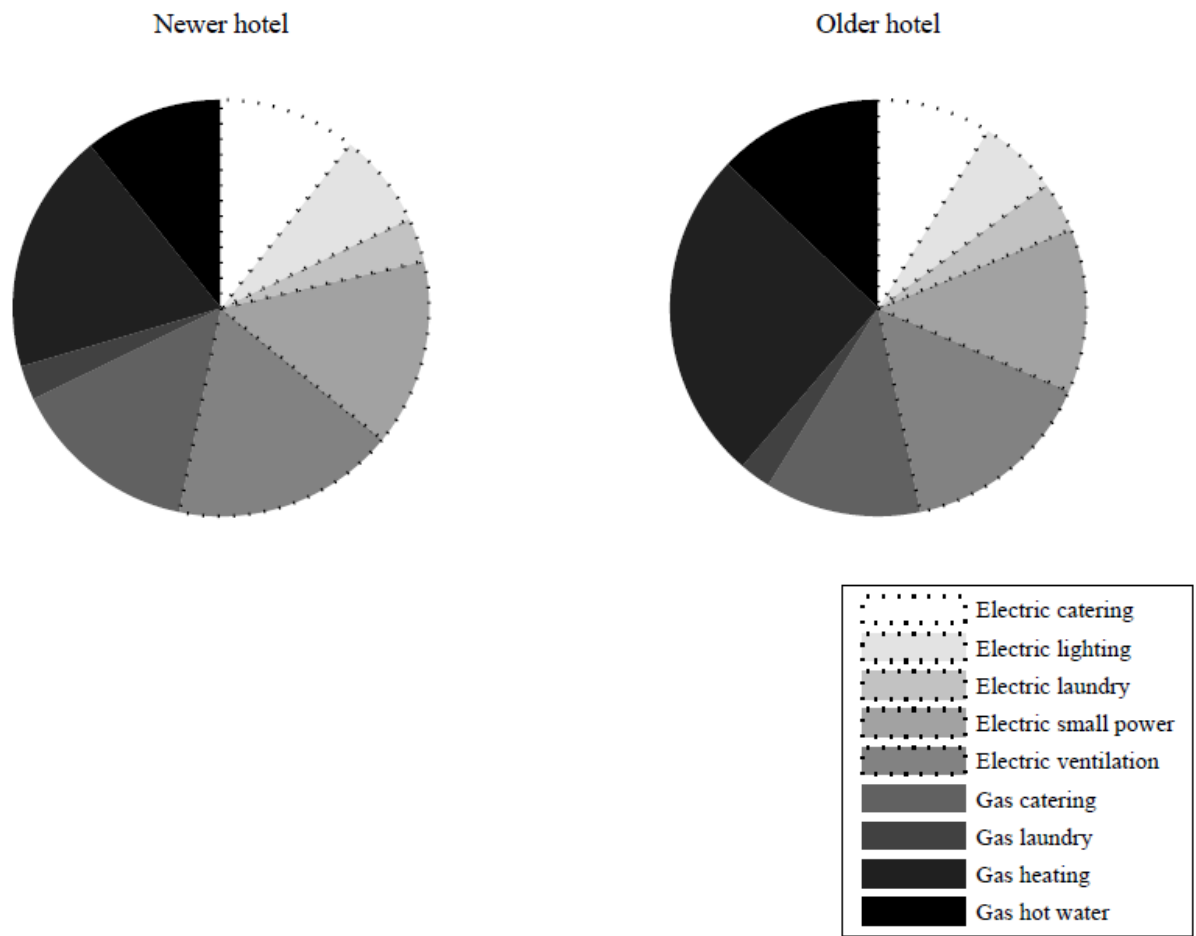

\section{Discussion}

\subsection{Effect of 2030 climate}

The decrease in heating energy consumption resulting from the change to a 2030 climate was partly offset by the increased ventilation due to the introduction of 2006 standards. Separate simulations showed that the effect on the heating energy consumption of the 2030 climate alone was in line with the change in the number of degree days.

\subsection{Effect of interventions}

All interventions had a significant impact, though the results for the insulation package 
should be treated with some caution. The main cause of the reduced emissions from the insulation package was not the improved wall insulation or glazing but the reduced infiltration. This finding should be considered as indicative rather than conclusive since it relies on estimates of both the infiltration in the building and its reduction due to the insulation and glazing changes. In reality, conditions in different buildings are likely to vary widely.

It is interesting that the effect of an intervention can vary depending on the point in the programme at which it is implemented. The effects found have not been very large, but they do mean that caution is required when drawing conclusions about the benefits of particular interventions.

The packages of interventions for the two hotels differed from each other because they were tailored for their target buildings and were in some cases limited by them. However, although the packages are not strictly comparable, it is worth considering how successful they were at achieving reductions in their corresponding hotels.

The overall effect of all of the interventions was greater in the newer hotel. The $50 \%$ reduction target was achieved without the need for the P \& L or solar thermal interventions. Clearly this raises the possibility that different combinations of the interventions available could be used to achieve the $50 \%$ target. The main reason for this success was that initially the hotel was electrically heated, so a major emissions reduction was achieved by simply switching to a gas condensing boiler.

By contrast, the older hotel only just achieved a 50\% reduction in emissions. Since it was already heated by gas, the emissions improvement from switching to a condensing boiler was relatively small. The limited roof area also limited the scope for the solar thermal intervention, while the degree of wall insulation was limited by the requirement to insulate internally to avoid affecting the external appearance. 


\subsection{Reliability of results}

The sensitivity analysis presented in Figs. 8 and 9 suggests that the most important threat to the $50 \%$ reduction target would be an increase in the carbon intensity of grid electricity. The likely figure in 2030 is difficult to predict. Current trends suggest an increase due to greater use of coal generation because of the cost of gas. However, the planned increase in renewables, to which the UK government is committed, suggests that the carbon intensity could go down in the longer term.

The reduction in the sensitivity of the emissions reduction to the carbon intensity shown in Fig. 10 is a simple consequence of the reduction in the use of grid electricity. Further reductions in both emissions and sensitivity would come from the adoption of renewable generation technologies as described in Section 4.5.

Another way of looking at the reliability of the results is to consider the practicality of the measures considered. The issue here is not economics, which is not addressed in this paper, but feasibility in the context of a hotel. Most of the interventions proposed use technologies which are already mature, with examples implemented in a wide range of buildings. Importantly, none would inconvenience guests, and most would be invisible. This suggests that guest acceptability would not be a barrier to the implementation of such changes.

An intervention that would not be invisible is solar thermal water heating in the newer hotel. Given the unsuitable orientation of the roof, the surface selected for installation of the panels was a new roof over the car park. This would have the benefit of providing shelter and would therefore potentially be seen as an enhancement to guests' comfort, besides the potential selling point that use of renewable generation equipment might present in the future when awareness of its value becomes more widespread. In any case, the newer hotel still achieves nearly $60 \%$ reductions without the solar thermal 
intervention.

\subsection{Interdependence of interventions}

The primary aim of the present work is to determine whether a halving of emissions by 2030 is technically possible, and to consider the ways of achieving this goal. The implied assumption is that all desired interventions are carried out in one operation, so that the question of ordering does not arise. In reality, however, this would not be the case. It takes time to complete major projects, and budgets are unlikely to cover the full set of proposed interventions. The issue that then needs to be addressed is the order in which the interventions should be carried out.

Subject to reasonable restrictions (e.g. that the timescales for any works are short), there are two main options for the guiding principle: at any stage in the process, the next intervention should provide either the maximum emissions reduction or the best value (maximum emissions reduction per unit cost). In principle, the latter approach could be represented in an emissions abatement curve (e.g. [30]) for the building in question.

However, the assumption here is that the effect of each intervention is independent of the stage at which it is implemented. In reality this is not the case. It is clear, for example, that an intervention that changes the emissions per unit heat demand, such as a change in the efficiency of a boiler, will have different effects on emissions depending upon whether it is implemented before or after an intervention that reduces the heating load, such as heat recovery or insulation.

But there are further effects. The clearest example uncovered in the present work is shown by the differences in emissions reduction attributable to the $\mathrm{P} \& \mathrm{~L}$ and the condensing boiler interventions when they were implemented in different orders, as described in Section 3.4. The P \& L intervention was much more effective when applied 
after the condensing boiler was fitted. The reason is straightforward. The improvement in the efficiency of electrical equipment as part of the P \& L intervention reduces the amount of heat added to the building. So during the winter period, the equipment contributes less to the heating of the building, and the heating system needs to do more as a result. When the heating is by electricity, this means that nothing has changed in the winter since electricity is still doing the heating. The only benefit of the P \& L intervention is in the summer period when the heating is not working. But when heating is by gas, part of the heating load is transferred from (effectively) electric to gas heating, resulting in a noticeable emissions reduction.

Another implication of carrying out interventions over an extended period relates to the practicalities of heating equipment. The above discussion and related arguments suggest that the emissions reductions associated with upgrading to a condensing boiler could be greater at the earlier stages of a refurbishment programme. However, determining the overall consequences of such an upgrade is not straightforward. Most of the other interventions cause significant reductions in the heating energy demand as shown in Figs. 6(b) and 7(b), so a boiler and heating system that are correctly sized for the initial stages will be significantly oversized later in the process. This would have a range of impacts: total costs would be higher than for a later replacement of smaller capacity; the radiators would become oversized as the heating demand decreased, enabling an efficiency increase due to the boiler spending more time in condensing mode; and operation on part-load could lead to higher or lower efficiency depending on the specific details of the system. On the other hand, delaying the condensing boiler installation until near the end (as in the reported modelling) means postponing significant, readily available and possibly cheaper emissions reductions. One response to this dilemma would be to encourage the application of a complete package of interventions as a single operation, to ensure the best balance of cost and emissions 
reduction. Another option might be the establishment of a boiler replacement market in which lower output equipment was provided as an exchange service.

The main implication of the above discussion is that the interactions of interventions, emissions and economics are complex and probably situation-specific. It may be that a consultancy service from an experienced practitioner would be required to deal with individual cases.

\subsection{Further reductions}

The interventions described achieved the aim of reducing the emissions to below the target level of $50 \%$. But it is useful to consider how much more could be achieved.

A technology that is often considered in non-domestic buildings is combined heat and power (CHP). To be worthwhile, there needs to be a constant demand for both heat and power, with the heat requirement in significant excess of that for power. In the present circumstances the ratio of heat to power shown in Fig. 7(b) for the older hotel is probably not suitable and that in Figure 6(b) for the newer hotel is certainly not, though this could change if a swimming pool were installed in the hotel. If CHP were appropriate, biomass firing would provide further emissions reductions, though there would be significant practical issues connected with fuel availability, delivery and storage.

In some of the equipment, further improvements in efficiency are possible. In particular, conservative estimates have been used for the power consumption of minibars, motors (in lifts and vacuum cleaners) and boilers. The sensitivity analysis in Fig. 9 shows, however, that the effect of any likely improvements on the overall emissions will be marginal.

Figure 11 shows that about half of the remaining emissions are from electricity use. 
Most of the items of equipment generating these emissions are not readily switched from electricity to alternative power sources. This suggests that renewable electricity generation technologies, such as solar photovoltaic or wind, or the use of green electricity tariffs, offer the best opportunities for further reductions.

\subsection{Future work}

Economics plays no real role in the present work, the aim of which has been to investigate the technical feasibility of emissions reductions in hotels. A future task might be to assess the economics of the measures described. However, the discussion of order dependence suggests that an economic assessment in the form of a simple emissions abatement curve might not be straightforward.

However, a more sophisticated approach may allow such a curve to be generated, perhaps by determining the possible variations and working with averages, or by modelling the approaches in sufficient detail to capture the order dependence. In any case, an injection of economics is still needed for budgeting and deciding on the set of measures that would be included in a package. This might allow the definition of generic protocols for emissions reduction measures, but it is likely, as implied by the above discussion, that significant individual tailoring will be needed.

The discussion demonstrates that there are significant practical issues connected with the stage at which a condensing boiler is installed. Further modelling with explicit consideration of the part-load performance would help to resolve the issue of when the boiler should be fitted.

An exploration of the potential for use of further renewable technologies, as mentioned in Section 4.5, or a ground-source heat pump, would be worthwhile to see how much further the emissions could be reduced. 
The overall trend of the interventions has been to reduce energy consumption and to move from electricity to gas. This latter trend, although appropriate for emissions reduction, may conflict with the need for energy security. Use of biomass may be a way of avoiding such difficulties. In the longer term, the move away from electricity could limit the opportunity to use the plentiful renewably-generated electricity that may become available in the future.

\section{Conclusions}

A modelling study has found that $50 \%$ reductions in greenhouse gas emissions from hotels are technically feasible, using mainly passive and mature technologies.

An increase in the carbon intensity of the electricity grid of $15 \%$ would prevent the achievement of the $50 \%$ emissions reduction target in the older hotel.

The main contributor to the emissions reduction of the insulation package was the infiltration reduction associated with the installation of the wall insulation and triple glazing, though the lack of accurate data for use in the calculation means that this finding should be seen as indicative rather than definitive.

Interactions between the different interventions mean that any package of measures must be carefully planned.

Further emissions reductions are possible. Achievement of an $80 \%$ emissions reductions target would require additional renewable or energy technologies to be used, such as ground source heat pumps, solar photovoltaics and biomass.

\section{Acknowledgments}

Thanks are due to Fulcrum Consulting for assistance in sizing building services, to Dr. Thomas Achtmanis for early work on the modelling and to TARBASE colleagues for 
useful discussions. The TARBASE project was funded by the UK Carbon Trust and EPSRC as part of the Carbon Vision Buildings programme (Grant no. GR/S94285/01). 


\section{Appendix: Proof of validity of ventilation heat recovery modelling method}

The aim is to demonstrate that recovering a proportion $\alpha$ of heat from air leaving a building is energetically equivalent to reducing the ventilation air flow rate by the same proportion.

Consider the system shown below. A ventilation heat recovery unit is set in an external wall separating the outside at temperature $T_{\text {ext }}$ from the inside at temperature $T_{i n t}$. Fresh air enters the unit at $T_{\text {ext }}$ and is warmed to $T_{\text {inlet }}$ by heat transferred from the exhaust air, which is thus cooled from $T_{\text {int }}$ to its exit temperature $T_{\text {exhaust }}$. The mass flow rate in each pipe is $\dot{m}$. Let the proportion of available heat recovered by the unit be $\alpha$.

Fig. A1. Ventilation heat recovery unit

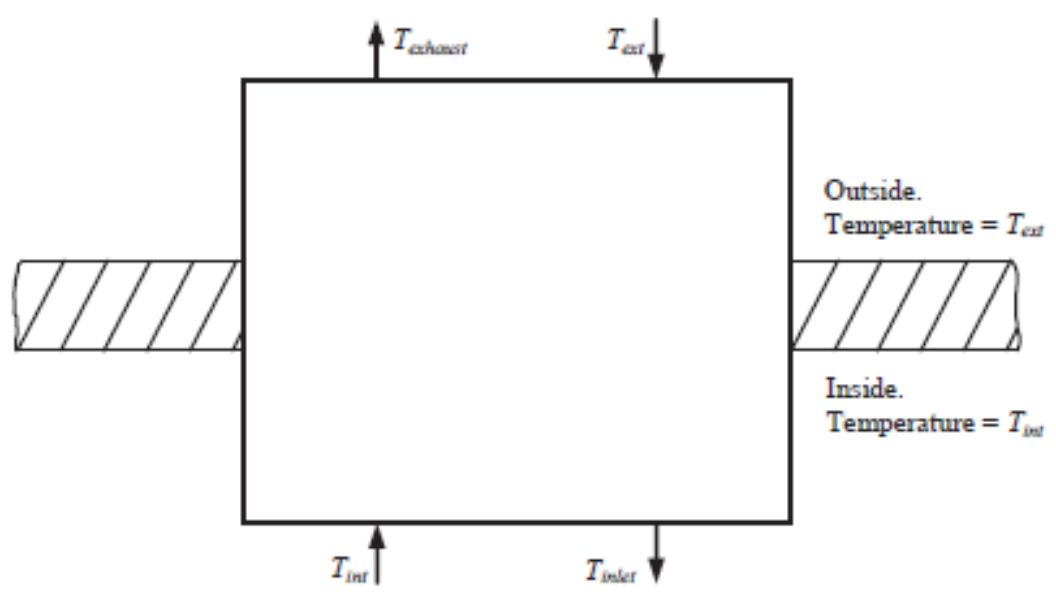

For the purposes of determining energy balances, suppose the flows are split within the unit as shown in Fig. A2. A proportion $\alpha$ of the incoming air is led through an ideal heat exchanger where it recovers all of the heat in the corresponding outgoing stream. The remainder $(1-\alpha)$ of the incoming air is simply mixed with the warmed stream before 
entering the building.

Similarly, the remainder $(1-\alpha)$ of the uncooled outgoing air is mixed with the cooled proportion $\alpha$ before being exhausted to the outside.

Fig. A2. Hypothetical internal structure of unit

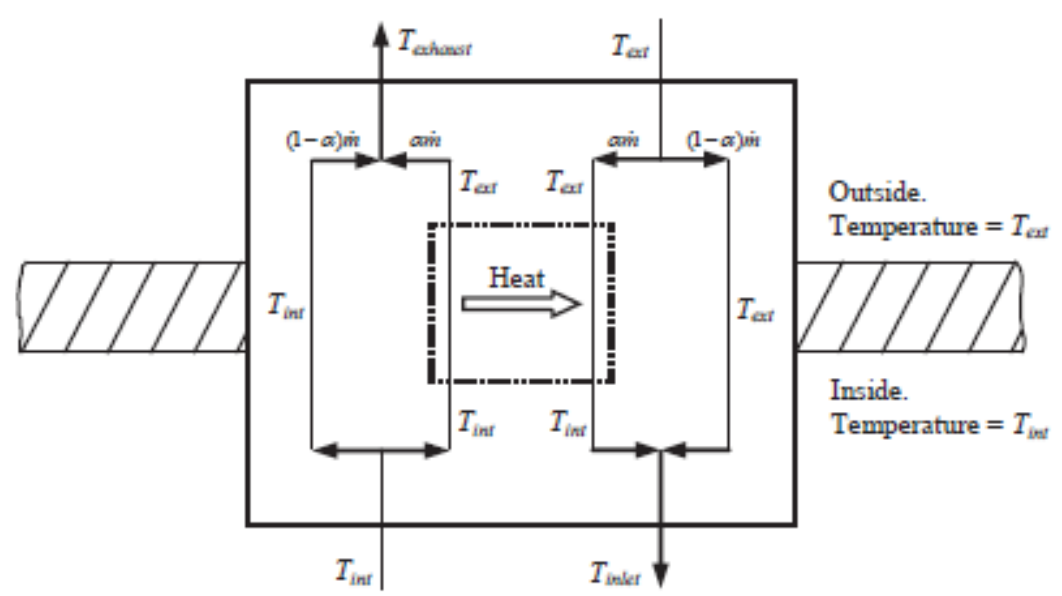

So the proportion of available heat recovered by the whole unit is

$\alpha \times 100 \%+(1-\alpha) \times 0 \%=\alpha$.

Although this is not a realistic arrangement, it correctly represents the energy and mass flows, as viewed from outside the box, for a system in which a proportion $\alpha$ of the available heat is recovered.

The reason for representing the flows in this way is that a change can be made within the dotted rectangle which replaces heat recovery by mass transfer but leaves the thermal behaviour unaffected as shown in Fig. A3. 
Fig. A3. Heat recovery converted to mass transfer

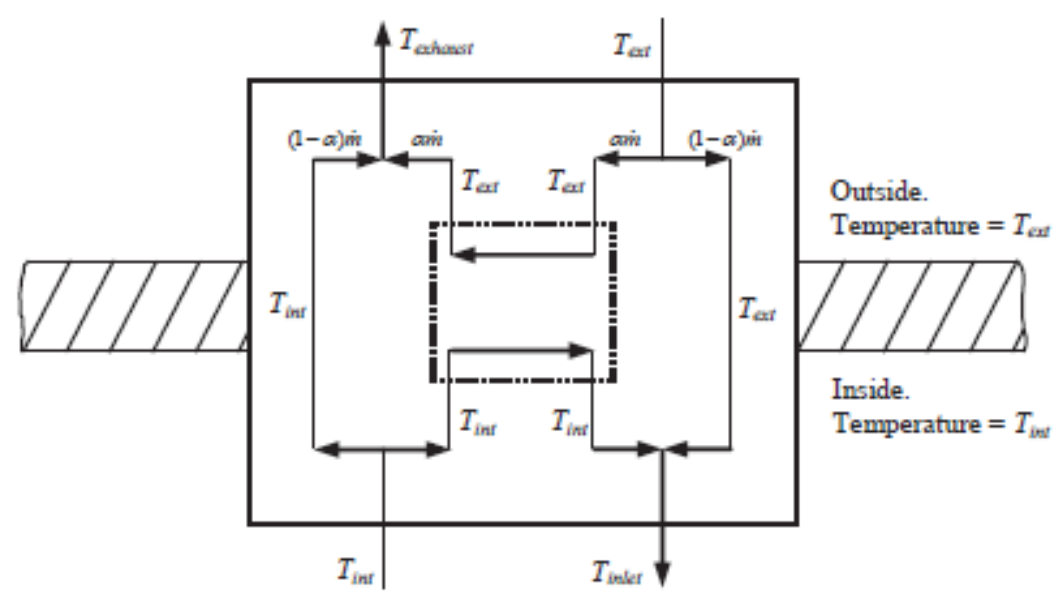

The two streams that pass through the dotted rectangle are simply removing air from the inside or outside and then returning it at the same temperature. Since this action has no effect on the energy balance, these streams are superfluous and can be removed.

The result of removing the superfluous streams is shown in Fig. A4.

Fig. A4. System after removal of superfluous streams

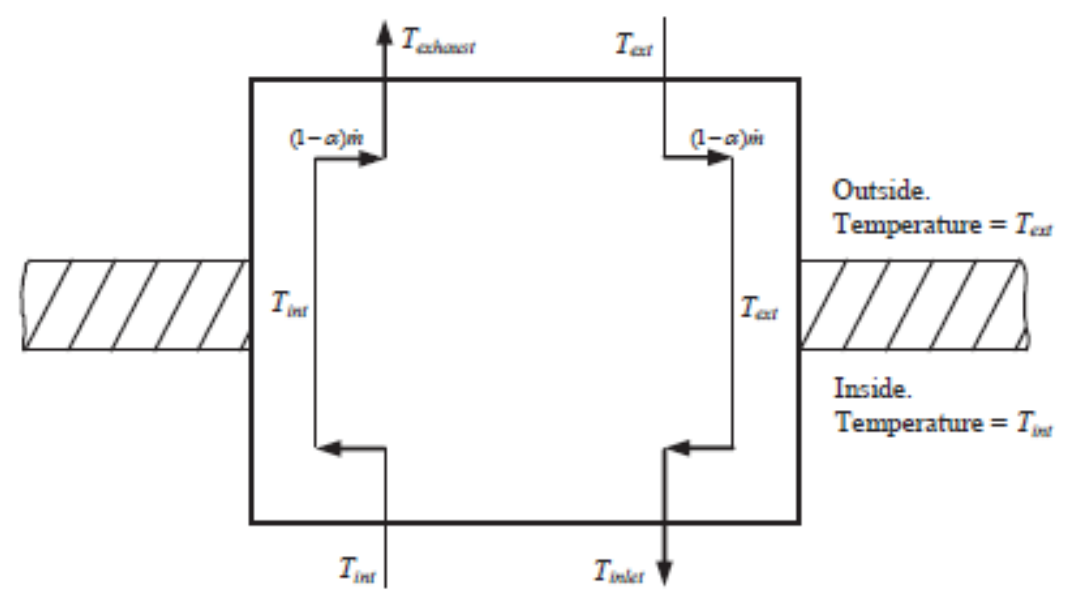


No heat transfer is now happening within the unit, so $T_{\text {inlet }}=T_{\text {ext }}$ and $T_{\text {exhaust }}=T_{\text {int }}$. So the system carries out ventilation with no heat recovery at a mass flow rate $(1-\alpha) \dot{m}$. Since no changes have been made that affect any heat flows outside the box, it is thermally equivalent to the system in Fig. A1 which recovers a proportion $\alpha$ of the available heat in a system in which the mass flow rate is $\dot{m}$.

So the thermal effects of ventilation heat recovery can be simulated precisely by reducing the ventilation rate by the proportion of heat recovered. 


\section{References}

[1] RCEP. Energy - The Changing Climate. Royal Commission on Environmental Pollution, June 2000.

[2] Official Journal of the European Communities. Directive 2002/91/EC of the European Parliament and of the Council of 16 December 2002 on the energy performance of buildings. 4.1.2003 L 1/65 - L 1/71.

[3] Carbon Trust. Reducing the carbon footprint for non-domestic buildings: a priority for the Carbon Trust. Presentation by David Vincent, Carbon Trust Technology Director. September 14, 2005. Available online:

http://www.resource05.co.uk/presentations/day2/David\%20Vincent.pdf, accessed $30^{\text {th }}$ November 2009.

[4] Carbon Trust, "Carbon Vision Buildings - Programme Plan” The Carbon Trust, London, 2004.

[5] Jenkins D, Liu Y, Peacock AD. Climatic and internal factors affecting future UK office heating and cooling energy consumptions. Energy and Buildings 2008; 40: 874881.

[6] Jenkins DP, Peacock AD, Banfill PFG. Will future low-carbon schools in the UK have an overheating problem? Building and Environment 2009; 44: 490-501.

[7] TARBASE project website. www.tarbase.com, accessed $27^{\text {th }}$ November 2009.

[8] BRE. Carbon dioxide emissions from non-domestic buildings: 2000 and beyond. BR 442, Building Research Establishment; 2002.

[9] Taylor SC. More efficient ESP-r modelling by automatic generation of input files. 11th Int. IBPSA Conf. (Building Simulation 2009), Glasgow, Scotland, July 27-30, 2009, pp. 1623-1627, (2009). 
[10] Defra. Guidelines to Defra's greenhouse gas conversion factors for company reporting - annexes (updated June 2008). Department for Environment, Food and Rural Affairs, UK; 2008. Available online:

http://www.defra.gov.uk/environment/business/reporting/pdf/ghg-cf-guidelinesannexes2008.pdf, accessed $27^{\text {th }}$ November 2009.

[11] CIBSE. Guide A: Environmental Design. London: Chartered Institution of Building Services Engineers; January 2006.

[12] McAllister JA, Farrell AE. Electricity consumption by battery-powered consumer electronics: A household-level survey. Energy 2007; 32: 1177-1184.

[13] MacKay DJC. Sustainable Energy - without the hot air. UIT Cambridge, 2008. Available online: www.withouthotair.com, accessed $27^{\text {th }}$ November 2009.

[14] Lockyer C, Scholarios D. Selecting hotel staff: why best practice does not always work. International Journal of Contemporary Hospitality Management 2004; 16: 125135.

[15] UK Occupancy Survey 2004. UK Occupancy Survey for Serviced Accommodation: Summary Report 2004. British Tourist Authority, Northern Ireland Tourist Board, VisitScotland and Wales Tourist Board.

[16] CIBSE. Guide A: Environmental Design. London: Chartered Institution of Building Services Engineers; October 1999.

[17] CIBSE. Guide B2: Ventilation and Air Conditioning. London: Chartered Institution of Building Services Engineers; 2001.

[18] Belcher SE, Hacker JN, Powell DS. Constructing design weather data for future climates. Building Services Engineering Research and Technology 2005; 26 (1): 49-61. [19] Stephen R. Airtightness in UK Dwellings. BRE Information Paper IP 1/00, January 
2000. Garston, Watford, Building Research Establishment, 2000.

[20] Johnston D, Wingfield J, Bell M. Airtightness of buildings - towards higher performance. Interim Report D1. Centre for the Built Environment, Leeds Metropolitan University, 2004. Available online:

http://www.lmu.ac.uk/as/cebe/projects/airtight/airtight1.pdf, accessed $27^{\text {th }}$ November 2009.

[21] Morgan C. Design and detailing for airtightness - SEDA Design Guide for Scotland No. 2. SEDA, 2006.

[22] CIBSE. Testing buildings for air leakage. Technical Memorandum TM23. London: Chartered Institute of Building Services Engineers, 2000.

[23] MTP. Framework Directive for the Eco-design of Energy Using Products (EuP). Market Transformation Programme; 2008. Available online:

http://www.mtprog.com/cms/eup/, accessed $27^{\text {th }}$ November 2009.

[24] Lane K. Labelling domestic ovens (Save study 4.1031/D/97-047). In: 2nd International Conference on Energy Efficiency in Household Appliances and Lighting, Naples, Italy, 27-29 September, 2000.

[25] Deru M, Torcellini P, Bottom K, Ault R. Analysis of NREL Cold-Drink Vending Machines for Energy Savings. National Renewable Energy Laboratory Golden, Colorado, USA; June 2003. Available online: http://www.nrel.gov/docs/fy03osti/34008.pdf, accessed 27th November 2009. [26] CEEP. Developing Statewide Commercial Foodservice Appliance Rebates. California Energy Efficiency Program, February 23, 2005. Available online: http://www.mass.gov/Eoeea/docs/dpu/gas/08-119/31109negfra2.pdf accessed 27th November 2009. 
[27] Fisher D. Is There Energy Start Light in your Kitchen? Hotel F\&B

September/October 2007. Available online: http://www.hotelfandb.com/biol/septoct2007-energy-star-equipment.asp, accessed 27th November 2009.

[28] BRE. BREDEM-12 Model Description: 2001 Update. BR 438. Building Research Establishment, 2002.

[29] BRECSU. Energy Efficiency in Hotels - A Guide for Owners and Managers. Energy Consumption Guide 36, BRESCU, 1993.

[30] Toke D, Taylor SC. Demand Reduction in the UK - Some Selected Measures and Policy Mechanisms. Energy Policy 2007; 35: 2131-2140.

[31] Taylor SC, Achtmanis T, Shao L. 2009. Emissions reductions in hotels in 2030. 11th Int. IBPSA Conf. (Building Simulation 2009), Glasgow, Scotland, July 27-30, 2009, pp 104-111, (2009). 